\title{
Coagglutination (COA) test for the rapid diagnosis of cryptococcal meningitis
}

\author{
GRACE KOSHI*, V. ANANDI*, J. C. M. SHASTRYt, A. M. CHERIYAN $\ddagger$ and \\ J. ABRAHAM§
} Departments of “ Microbiology, †Nephrology, $¥$ Medicine and $\$$ Neurology, Christian Medical College Hospital,
Vellore 632, 004, South India

\begin{abstract}
Summary. Cryptococcus coagglutination (COA) test reagent was prepared locally and showed no cross reactions with different species of bacteria or yeasts or with 75 control sera including 25 that gave positive results for RA factor. We used the COA test to detect cryptococcus antigen in the CSF and we could confirm the diagnosis of 11 out of 115 suspected cases of fungal meningitis; the titre varied from 4 to 128 . A four-fold rise in titre confirmed the diagnostic value and a steady fall in titre in three patients on therapy indicated the prognostic value of the test. The earliest confirmation was in a renal transplant patient on the eighth day after onset of symptoms. The COA test was negative with the CSF of 118 patients with chronic meningitis. Cryptococcal colony forming units (cfu) in CSF varied from 100 to $>100000 / \mathrm{ml}$ and correlated well with microscopy and with the COA antigen titre in CSF. Four out of the 11 patients who had cryptococcaemia, had $50000-100000 \mathrm{cfu} / \mathrm{ml}$ in the CSF. Cryptococcus antigen was detected by COA in the serum of all 11 patients, even in those with only $100 \mathrm{cfu} / \mathrm{ml}$ in CSF. In the three post-renal transplant patients, who were being monitored regularly, the diagnosis was made early and all three recovered on antifungal therapy with no relapse to date (1-2 years). All the others, including the two primary CNS infections, succumbed to the disease because they presented late for diagnosis and therapy. The cryptococcus COA test is a simple and specific test that can be used as a rapid test to confirm early diagnosis and permit prompt therapy, which should improve the prognosis in CNS and other forms of systemic cryptococcosis. Moreover, it is reproducible and cost-effective, particularly in countries where the latex and other expensive test reagents are not generally available.
\end{abstract}

\section{Introduction}

Cryptococcosis of the central nervous system develops quite rapidly and results in progressive deterioration and death (Stein and Burdon, 1960; Fujita et al., 1981). Demonstration of capsulate yeast-like organisms by India ink preparation is a simple and rapid technique (Koshi et al., 1964; Ajello et al., 1966). When only a few organisms are present or in the early stages of the disease, demonstration of organisms by India ink may not always be successful. Cultural isolation and confirmation may take many days to weeks. The

Received 23 Sept. 1988; revised version accepted 12 Jan. 1989. *Correspondence should be sent to Dr G. Koshi, Department of Microbiology, M.O.S.C.M.M. Hospital, Kolenchery-682 311, Kerala, South India. fluorescent antibody test for cryptococcus, though rapid, may not be available to all.

Serological tests such as latex agglutination (LA), (Bindschadler and Bennett, 1968; Dolan, 1972) and complement fixation (CF) (Bindschadler and Bennett, 1968) have been described for the detection of cryptococcus antigen in meningitis and other forms of cryptococcosis. The staphylococcal coagglutination (COA) technique developed by Christensen $e t$ al. (1973) was applied by Maccani (1981) to the presumptive identification of Cryptococcus neoformans serotypes after isolation. We have extended the COA test for the rapid diagnosis of cryptococcal meningitis by antigen detection in CSF and for testing for antigenaemia in patients with cryptococcosis. Subsequently, we attempted to correlate the numbers of $C$. neoformans in the CSF and the detection of antigen in CSF or serum by the COA test. 


\section{Materials and methods}

\section{Controls}

Testing CSF from normal healthy individuals was not feasible in our study. However, sera from 50 normal healthy individuals and from 25 patients who were positive for rheumatoid arthritis (RA) factor were included as controls. Faeces, throat and skin swabs from the 50 healthy controls, cultured on Sabouraud Dextrose Agar (SDA) and Brain Heart Infusion Agar (BHIA) were negative for cryptococci.

\section{Subjects}

A group of 115 patients with suspected fungal meningitis and another group of 118 patients with chronic meningitis were included in the study.

\section{Examination of CSF}

CSF specimens from all patients were examined by Gram's stain and in India ink preparations. Repeat CSF specimens were examined at intervals of 2-10 days, 4-8 times in some patients. CSF sediments were cultured for yeasts on two sets of SDA and BHIA slopes, Beef Infusion Blood Agar (BIBA) plates, and in Thioglycollate Broth. One set of the slopes and plates was incubated at $37^{\circ} \mathrm{C}$ and the other at $25-30^{\circ} \mathrm{C}$; the thioglycollate broths were incubated at $37^{\circ} \mathrm{C}$. For colony counts, $0.01 \mathrm{ml}$, sampled with a standard 4-mm platinum loop, was streaked on a BHIA plate and incubated at $37^{\circ} \mathrm{C}$. Conventional methods (Ajello et al., 1966) were followed for the identification of $C$. neoformans; these included fermentation reactions and assimilation of various sugars, nitrate reduction, urease and oxidase tests, and chlamydospore and germ-tube formation.

Animal pathogenicity of all $11 C$. neoformans isolates was tested by intracerebral and intraperitoneal inoculation of 4-week-old white mice, two animals being used for each route (Khan et al., 1959). The mice were killed when the intracerebrally inoculated animals showed signs of sickness between the 6th and the 14th day (ruffling of fur, swelling of head and drowsiness), but before death so as to recover the organisms with capsules intact. The mice inoculated intraperitoneally showed signs of sickness between the 20th and the 40th day.

\section{Cryptococcus neoformans COA test}

Concurrent with the mycological examination, $0.5 \mathrm{ml}$ of CSF was first inactivated by heating in a water bath at $100^{\circ} \mathrm{C}$ for $30 \mathrm{~min}$, cooled and tested by COA. Tests were performed on a ceramic ring slide with $0.05 \mathrm{ml}$ of both heated $\mathrm{CSF}$ and $\mathrm{COA}$ reagent.

$C$. neoformans polysaccharide antigen prepared as recommended by Scott $e t$ al. (1980) and PBS were used as positive and negative controls respectively. Each CSF was also tested with staphylococci treated with preimmune rabbit serum (PIS) to exclude nonspecific reactions. The clumping and clearing of positive reactions were very easily observed and they were graded from $1+$ to $4+$ reactions.

Furthermore, sera from 40 of the 115 subjects with suspected fungal meningitis, including the 11 patients who yielded cryptococci from CSF cultures, were also tested for antigen detection by the COA test. Blood from all 40 patients was also cultured for yeasts (Myers and Koshi, 1982), but not quantitatively.

\section{COA blocking test}

To confirm the specificity of the COA reaction, a blocking test was performed. For this, $50 \mu 1$ of heat treated CSF at the dilution at which COA was maximal, was mixed with $50 \mu \mathrm{l}$ of $C$. neoformans antiserum. The mixture was incubated at $37^{\circ} \mathrm{C}$ for $30 \mathrm{~min}$ and centrifuged at $2500 \mathrm{rpm}$ for $15 \mathrm{~min}$, and the supernate was tested in the COA test, to note whether the cryptococcus antigen present in the CSF was specifically blocked by the $C$. neoformans antiserum.

The COA-positive samples were also tested for the presence of RA factor by a commercial RA kit.

\section{C. neoformans antiserum production}

Antiserum to $C$. neoformans for the $\mathrm{COA}$ reagent preparations was produced in rabbits according to the method of Ikeda et al. (1982), by inoculation of a heat killed suspension of $C$. neoformans serotype A (Courtesy Dr Reiss, Division of Immunology, CDC, Atlanta). The hyperimmune serum was checked by the slide agglutination method of Maccani (1981) with the immunising strain as antigen.

\section{C. neoformans $C O A$ reagent preparation}

The method of COA reagent production was essentially similar to that of Candida albicans COA reagent (Koshi et al., 1987). C. neoformans rabbit antiserum, $0 \cdot 1 \mathrm{ml}$, was mixed with $1.0 \mathrm{ml}$ of $10 \%$ suspension of Cowan I Staphylococcus aureus (Christensen et al., 1973; Koshi et al., 1979; Maccani, 1981; Koshi et al., 1987). The mixture was left at room temperature for $3 \mathrm{~h}$. As controls, staphylococcal cells were sensitised similarly with PIS. The sensitised reagents were washed once with $0.03 \mathrm{M}$ phosphate buffered saline (PBS) and made up to a $1 \%$ suspension of cryptococcus COA reagent and stored at $4^{\circ} \mathrm{C}$ until use.

To study cross reactivity, the cryptococcus COA reagent was tested with $C$. neoformans serotypes $\mathrm{B}, \mathrm{C}$ and $D$, various candida species, and representative bacterial species including $S$. aureus, streptococci of groups A, B and C, Streptococcus pneumoniae, Neisseria meningitidis, Escherichia coli, Klebsiella sp. and Salmonella typhi. No strain of Trichosporon was available to check crossreactivity. 


\section{Results}

The locally produced $C$. neoformans antiserum gave a slide agglutination titre of 128 with C.neoformans serotype $\mathrm{A}$ and, at the reference centre CDC, Atlanta, GA, the tube agglutination titre was found to be 512 . The COA reagent produced with this antiserum was stable at $4^{\circ} \mathrm{C}$ for 9 months.

Cryptococcus COA reagent did not cross-react with the various bacterial and candida strains. However, it did react with $C$. neoformans serotypes $B, C$ and $D$ to yield $2+, 3+$ and $4+$ reactions respectively.

Cryptococci were isolated on several media from the CSF of all 11 patients and the blood of four. All 11 isolates gave typical reactions in sugar assimilation and fermentation tests, nitrate was not reduced, and oxidase and urease tests were positive; two of the 11 showed short pseudohyphae-like structures in culture. (Silva-Hunter and Cooper, 1980). In mouse pathogenicity tests, cryptococci with capsules were demonstrated in heart blood and distant organs such as liver, spleen and lungs in all mice inoculated i.p. and in the brain of mice inoculated i.c. ; the organisms were confirmed as $C$. neoformans. One strain from a patient with cryptococcaemia sent to $\mathrm{CDC}$, Atlanta, was confirmed as $C$. neoformans var. gatti (serotype B/C).

The results of the cryptococcus COA test and culture of CSF and blood from patients with suspected cryptococcal meningitis and from controls are given in table I. The COA test detected cryptococcus antigen in the CSF of 11 of 115 patients, whereas Gram's stain and India ink preparations were positive in only nine on first examination, although all 11 became positive by India ink on repeat examination. Culture yielded $C$. neoformans from the CSF of all 11 patients but from the blood of only four. COA test and culture were negative with the CSF of 118 patients with chronic meningitis; the sera of 50 healthy controls and 25 sera that gave positive results for RA factor, gave negative results in the COA test.

Correlation of COA titres in the CSF and serum of the 11 patients with the quantitative culture results, clinical findings, therapy and outcome are shown in table II. The COA titre in CSF varied from 8 to 128 and in the serum, from neat to 8 . The cfu in CSF varied from 100 to $>100000 / \mathrm{ml}$. although antigen was demonstrated by COA in the serum of all 11 patients, only four patients had cryptococcaemia. The rise and fall in titre of the COA test in repeat tests of CSF and sera done at intervals of 2-10 days are also given in table II; only a few of the repeated tests done are shown in the table.

\section{Discussion}

Rapid diagnosis of cryptococcal meningitis is necessary for timely therapy and improved prognosis. Detection of fungal antigen in serum or body fluids has been found to be more promising than antibody detection (Bindschadler and Bennett, 1968; Dolan, 1972; Kaufman and Blumer, 1973). The LA test, which is sensitive, is widely used as a

Table I. Comparison of cryptococcus COA test and culture for C. neoformans in patients with suspected fungal meningitis, chronic meningitis and controls

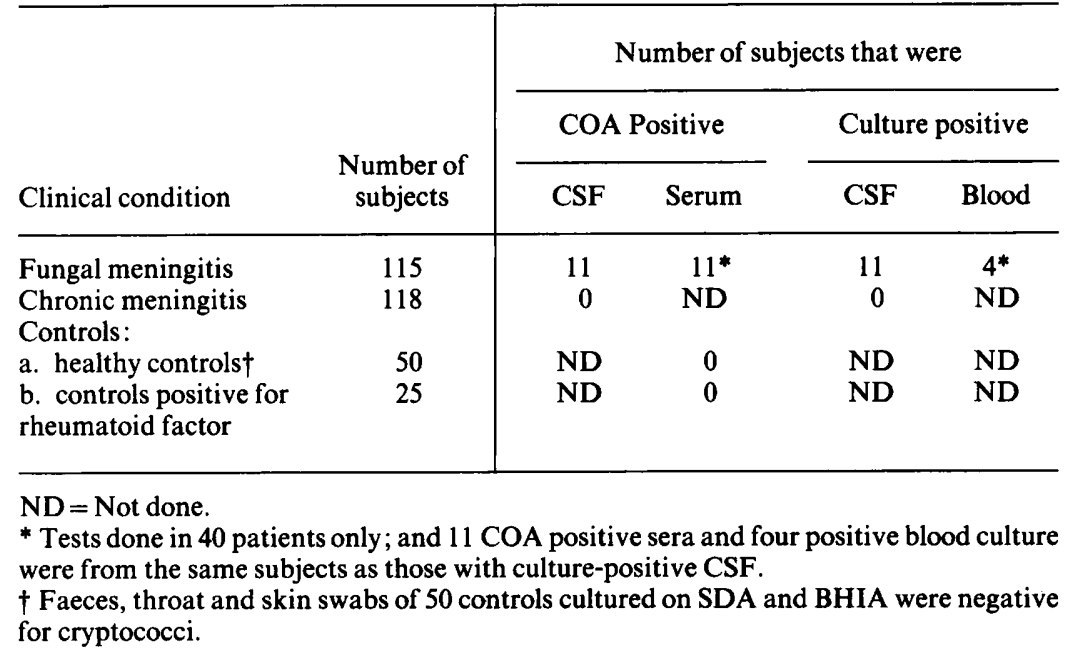


rapid test, but may yield false positive reactions due to the presence of RA factors (Dolan, 1972; Kaufman and Blumer, 1973).

The COA test used for the rapid identification of bacterial antigens has been effectively applied by us (Koshi et al., 1987) to detect candida antigen in the serum and cyst fluid of patients with candidaemia and other candida lesions. Therefore, we extended the COA test to detect cryptococcus antigen in the CSF and serum of patients with meningitis.

The cryptococcus COA test was found to be specific for cryptococcus antigen detection because of the absence of cross-reactions with various bacterial and fungal agents, as well as its lack of reactivity with 75 control sera, including 25 that were positive for RA factor. Moreover, the blocking test we used tended to confirm the specificity of the test.

Of the 115 patients suspected of fungal meningitis, antigen was detected by the COA test in the CSF of 11 culturally confirmed cases (table I): of these, two had primary meningitis and all the rest were secondary. Five of the latter had cirrhosis or other hepatic problems, three were post-renal transplantation and on immunosuppressive therapy, and one, a patient with chronic collagen disease, was on long term steroids.

The titre of antigen in the CSF varied from 8 to 128 by the COA test. Cryptococci were detected by Gram's stain and India ink in the CSF of 9 out of the 11 patients initially and all 11 patients on repeat examinations. The viable count of cryptococci in CSF varied from 100 to $>100000 \mathrm{cfu} / \mathrm{ml}$ (table II). There was a correlation between the microscopic findings, the $\mathrm{cfu} / \mathrm{ml}$ and the titre of antigen in the CSF. Four out of the five patients with > $100000 \mathrm{cfu} / \mathrm{ml}$ had a COA titre of 128 and in the fifth patient the titre was 64. In two cases, microscopic examination was negative initially, but became positive when the CSF counts rose from 100 and 800 to 50000 and 1200 cells $/ \mathrm{ml}$ respectively. Nevertheless, $\mathrm{COA}$ gave positive results even when microscopy was negative; COA was also positive in neat serum when CSF contained low numbers of cryptococci (e.g. even when as low as $100 \mathrm{cfu} / \mathrm{ml})$.

Perfect et al. (1983) found that the CSF in four patients with cryptococcal meningitis contained $10^{4}-10^{7} \mathrm{cfu} / \mathrm{ml}$ before antifungal therapy was begun. Quantitative counts were done in all of our 11 patients. In the two patients with primary cryptococcal meningitis, the COA test in CSF gave high titres and was positive in serum (titre 4); cryptococci were cultured in large numbers from CSF, i.e.
100000 and $50000 \mathrm{cfu} / \mathrm{ml}$ respectively and were demonstrable with India ink: blood cultures were negative. Antifungal therapy was started too late in these patients and both succumbed to the disease.

In the group of patients with secondary cryptococcosis, among the five with cirrhosis or other hepatic diseases, all except one, who had tuberculosis, had very high cfu counts and COA titres in CSF; the COA was also positive in the serum; Gram's stain and India ink preparation of CSF were also positive (table II). Antifungal therapy was not instituted in three of these patients, and in two amphotericin B and 5-fluorocytosine were only given 30-36 days after onset and the patients died subsequently.

The patient with collagen disease and on steroids was admitted comatose and died within $72 \mathrm{~h}$ of admission without antifungal therapy. The steroid therapy probably aggravated the superinfection.

In the three post-renal transplant patients on immunosuppressive therapy the specific diagnosis was made within 8-15 days after onset of symptoms. Because of regular monitoring and the early institution of amphotericin B and 5-fluorocytosine, all three patients were discharged fully recovered and were doing well up to the date of this report (12 years).

The many repeat COA tests and repeat cultures of CSF and blood yielded important information. A four-fold rise or fall in titre of COA was noted in six patients and a two-fold rise in three patients in whom the repeat test was made after a short interval. Thus the early diagnostic importance of the COA test was undoubted in the renal transplant and in the post-liver disease patients. The early confirmation of diagnosis enabled us to institute specific therapy as early as the 8th to the 16th day after onset. Perfect et al. (1983) also found a favourable outcome in patients who had early antifungal therapy.

Persistently high antigen titres in the CSF measured by LA test, even after antifungal therapy, were reported by Lauter (1977) and Sapico (1979). We found that the cryptococcus antigen in CSF decreased steadily with antifungal therapy; in the three renal transplant patients, the COA titre became negative on the 32nd, 40th and 44th day respectively (table II).

The four patients in our series who had cryptococcaemia had secondary cryptococcal meningitis and were on steroids; two had liver disease, one had collagen vascular disease and the fourth was a post-renal transplant patient. Butler et al. (1964) reported that $12.5 \%$ of their 40 cryptococcal meningitis patients had positive blood cultures. In 
Table II. Clinical and laboratory findings in patients with cryptococcal meningitis

\begin{tabular}{|c|c|c|c|c|c|c|c|}
\hline \multirow{2}{*}{$\begin{array}{l}\text { Case no., } \\
\text { Age, Sex }\end{array}$} & \multirow[b]{2}{*}{ Clinical findings } & \multirow{2}{*}{$\begin{array}{l}\text { Date of test } \\
\text { after onset } \\
\text { (days) }\end{array}$} & \multirow{2}{*}{$\begin{array}{l}\text { C. neoformans } \\
\mathrm{cfu} / \mathrm{ml} \mathrm{CSF}\end{array}$} & \multicolumn{2}{|c|}{ COA titre } & \multirow[b]{2}{*}{ Therapy } & \multirow[b]{2}{*}{ Outcome } \\
\hline & & & & CSF & Serum & & \\
\hline \multicolumn{8}{|c|}{ I Primary meningitis } \\
\hline 1. $16, \mathrm{M}$ & 2 months, severe 2 weeks & 90 & $>100000$ & 128 & 4 & IVAB* & died \\
\hline 2. $35, \mathrm{~F}$ & 1 month, severe 1 week & 32 & 50000 & 32 & ND & IVAB & died \\
\hline \multicolumn{8}{|c|}{ II Secondary meningitis, hepatic disease } \\
\hline \multirow[t]{3}{*}{ 3. $40, \mathrm{M}$} & cirrhosis 3 years & 32 & 90000 & 64 & 4 & IVAB & died \\
\hline & steroids 2 years & 40 & -.. & 16 & ND & & \\
\hline & meningitis 3 weeks & 50 & --- & 4 & ND & & \\
\hline \multirow[t]{2}{*}{ 4. $65, \mathrm{M}$} & cirrhosis 3 years & 15 & $>100000$ & 64 & 8 & $\cdots$ & died \\
\hline & $\begin{array}{l}\text { steroids } 1 \text { year } \\
\text { meningitis } 3 \text { weeks }\end{array}$ & & & & & & \\
\hline \multirow[t]{2}{*}{ 5. $45 . \mathrm{M}$} & cirrhosis 20 years & 30 & $>60000$ & 16 & 2 & IVAB-Fl* ${ }^{*}$ & died \\
\hline & $\begin{array}{l}\text { steroids } 1 \text { year } \\
\text { meningitis } 3 \text { weeks }\end{array}$ & 35 & $>100000$ & 128 & 8 & & \\
\hline \multirow[t]{3}{*}{$631, \mathrm{M}$} & cirrhosis 3 years & 18 & $>100000$ & 64 & neat & $\cdots$ & died \\
\hline & steroids 1 year & 20 & $>100000$ & 128 & 2 & & \\
\hline & meningitis 3 weeks & 22 & ND & ND & 4 & & \\
\hline \multirow[t]{2}{*}{ 7. $56, \mathrm{M}$} & chronic liver disease & 15 & 100 & 4 & neat & $\cdots$ & unknown \\
\hline & tuberculosis 1 year & 18 & 1200 & 16 & 2 & & \\
\hline \multirow[t]{2}{*}{ 8. $47, \mathrm{~F}$} & $\begin{array}{l}\text { collagen disease several } \\
\text { years }\end{array}$ & 60 & $>100000$ & 64 & 4 & --- & $\begin{array}{l}\text { died within } \\
72 \mathrm{~h}\end{array}$ \\
\hline & $\begin{array}{l}\text { steroids } 1 \text { year } \\
\text { meningitis } 2 \text { months }\end{array}$ & 62 & $>100000$ & 128 & ND & & \\
\hline \multicolumn{8}{|c|}{ III Meningitis, renal transplant } \\
\hline \multirow{5}{*}{ 9. $45, \mathrm{M}$} & renal transplantation & 15 & 800 & 16 & 2 & IVAB-FI & recovered \\
\hline & and steroids 9 years & 19 & 1000 & 16 & 2 & & \\
\hline & diabetes 3 years & 25 & --. & neat & -.. & & \\
\hline & meningitis 2 weeks & 32 & -- & $\cdots$ & -.- & & \\
\hline & & 69 & ... & --- & -.- & & \\
\hline \multirow[t]{4}{*}{ 10. $42, \mathrm{~F}$} & chronic renal disease & 8 & 1400 & 8 & 2 & IVAB-FI & recovered \\
\hline & $\begin{array}{l}3 \text { years } \\
\text { steroids } 1 \text { month }\end{array}$ & 11 & 3100 & 8 & 2 & & \\
\hline & meningitis 1 week & 40 & $\cdots$ & 2 & ND & & \\
\hline & & 60 & -.- & $\ldots$ & ND & & \\
\hline \multirow[t]{3}{*}{ 11. $46, \mathrm{M}$} & renal transplantation & 14 & 50000 & 8 & 4 & IVAB-FI & recovered \\
\hline & steroids 3 months & 22 & -- & neat & ND & & \\
\hline & meningitis 2 weeks & 44 & --. & -- & ND & & \\
\hline
\end{tabular}

* IVAB = intravenous amphotericin B.

* IVAB-Fl = intravenous amphotericin B + 5-fluorocytosine.

this study we have shown that whereas only four of the 11 meningitis patients had cryptococcaemia, all had antigenaemia. Blood is inhibitory to the growth of cryptococci when specific host factors are inactive and a large tissue burden of organisms is needed for detection of cryptococci in blood culture (Perfect et al., 1983). Hence our study suggests that antigen detection in serum helps in early diagnosis of cryptococcaemia.

The COA test which we applied for cryptococcal antigen detection in CSF and serum has been found to be a simple, sensitive, rapid and cost effective test, specific enough for the diagnosis of suspected cryptococcal meningitis. The early diagnostic and prognostic value of the test is noteworthy; it can be used as a rapid test to make the diagnosis early and permit prompt therapy which should improve the prognosis.

We thank Dr L. Kaufman, Division of Immunology and Fungal Diseases, CDC, Atlanta, USA, for determining the titre of the C.neoformans antiserum and Drs D. Mathai and Lilly John, Department of Medicine and Dr G. Kurian, Department of Gastroenterology, Christian Medical College and Hospital, Vellore for their co-operation and heip. 


\section{REFERENCES}

Ajello L, Georg L K, Kaplan W, Kaufman L 1966 The yeastlike fungi. In: Laboratory manual for medical mycology, section E. Communicable Diseases Center, U.S. Department of Health, Education and Welfare. Public Health Service, E1.

Bindschadler D D, Bennett J E 1968 Serology of human cryptococcosis. Annals of Internal Medicine 69: 45-52.

Butler W T, Alling D W, Spickard A, Utz J P 1964 Diagnostic and prognostic value of clinical and laboratory findings in cryptococcal meningitis, a follow-up study of forty patients. New Zealand Journal of Medicine 270: 59-62.

Christensen P, Kahlmeter G, Johnson S, Kronvall G 1973 New method for the serological grouping of streptococci with specific antibodies absorbed in protein A-containing staphylococci. Infection and Immunity $7:$ :881-885.

Dolan C T 1972 Specificity of the latex-Cryptococcal antigen test. American Journal of Clinical Pathology 58: 358-364.

Fujita N K, Reynard M, Sapico F L, Guze L B, Edwards J E 1981 Cryptococcal intracerebral mass lesions. Annals of Internal Medicine 94 : 382-388.

Ikeda R, Shihoda T, Fukazawa Y, Kaufman L 1982 Antigenic characterisation of Cryptococcus neoformans serotypes and its application to serotyping of clinical isolates. Journal of Clinical Microbiology 16: 22-29.

Kaufman L, Blumer S 1973 Latex-cryptococcal antigen test. American Journal of Clinical Pathology 60: 285-286.

Khan M J, Myers R, Koshi G 1959 Pulmonary cryptococcosis, a case report and experimental study. Diseases of the Chest 36: 656-660.

Koshi G, Sudersanam D, Selvapandian A J, Myers R M 1964 Cryptococcosis 'masquerading' as tuberculosis of the spine. Indian Journal of Pathology and Bacteriology 7: 264-271.
Koshi G, Thangavelu C P, Brahmadathan K N 1979 The reliability and rapidity of the coagglutination technique and its comparison with precipitin technics in the grouping of streptococci. American Journal of Clinical Pathology 71 : 709-712.

Koshi G, Viswanath A, Chandy M, Jairaj P S 1987 Development of a coagglutination (COA) technique to detect candida antigenemia. I. COA versus candida isolation. American Journal of Clinical Pathology 88: 429-435.

Lauter C B 1977 Commercial test sensitivity to cryptococcal antigen (letter). Annals of Internal Medicine 86: 240.

Maccani J E 1981 Rapid presumptive identification of Cryptococcus neoformans by staphylococcal coagglutination. Journal of Clinical Microbiology 13: 828-832.

Myers R M, Koshi G 1982 Blood. In: Diagnostic procedures in medical microbiology and immunology/serology, Chapter 3, Part II. IELC Concordia Press and Training Institute, Vaniyambadi 635 751, Tamil Nadu, p 19.

Perfect J R, Durack D T, Gallis H A 1983 Cryptococcemia. Medicine 62: 98-109.

Sapico F L 1979 Disappearance of focal cryptococcal brain lesion on chemotherapy alone (letter). Lancet $1: 560$.

Scott E N, Muchmore H G, Felton F G 1980 Comparisons of enzyme immunoassay and latex agglutination methods for detection of Cryptococcus neoformans antigen. American Journal of Clinical Pathology 73: 790-794.

Silva-Hunter M, Cooper B H 1980 Yeasts of medical importance. In: Lennette $\mathrm{E} \mathrm{H}$ et al. (eds.) Manual of clinical microbiology, 3rd edn. American Society for Microbiology, Washington DC, pp 562-576.

Stein J M, Burdon P J 1960 Cryptococcus neoformans infection of the central nervous system: A case treated by amphotericin B with post-mortem examination. Annals of Internal Medicine 52: 445-453. 